\title{
Accuracy in use of adrenalin auto-injectors in a simulated emergency situation: a comparison of JEXT, EpiPen and Emerade
}

\author{
Rebecca Knibb, Kirsty Morton \\ From Food Allergy and Anaphylaxis Meeting 2014 \\ Dublin, Ireland. 9-11 October 2014
}

Correct use of an adrenalin auto-injector (AAI) is vital in an emergency situation where a person has gone into anaphylactic shock. Studies have shown that nearly half of untrained participants are unable to correctly use an AAI training device after instruction. Emerade is an AAI with a different design for use, with pictures providing instructions. This study aimed to assess intuitiveness and accuracy of use of JEXT, EpiPen and Emerade in untrained, non-allergic participants, in a simulated emergency situation.

Participants ( $\mathrm{n}=90$ adults) were randomly assigned to JEXT, EpiPen or Emerade. A simulated scenario involved a live patient acting unconscious after eating something they were allergic to; a loud ambulance siren played throughout. Participants were asked to give the person an injection of adrenalin in the leg, using a trainer pen with no instructions available. They were then asked to give a second shot with a pen of the same design with instructions. The simulation was scored by the researcher and video recorded; participants were interviewed about their experience.

No participant using EpiPen or JEXT successfully gave their patient adrenalin when they had no instructions to go by, compared to $82 \%$ using Emerade ( $<<0.001)$. After reading instructions, significantly more participants successfully gave their patient adrenalin using Emerade (100\%) compared to JEXT (64\%) or EpiPen (33\%), $\mathrm{p}<0.001$. Participants also took significantly less time to administer adrenalin with Emerade (mean $=14.73$ seconds), compared to JEXT (29.21) or EpiPen (33.72), $\mathrm{p}<0.001$. Instructions on JEXT and EpiPen were confusing and skim read by participants, thus they missed important information. Emerade was reported to be easy

Aston University, Birmingham, UK

(c) 2015 Knibb and Morton; licensee BioMed Central Ltd. This is an Open Access article distributed under the terms of the Creative Commons Attribution License (http://creativecommons.org/licenses/by/4.0), which permits unrestricted use, distribution, and reproduction in any medium, provided the original work is properly cited. The Creative Commons Public Domain Dedication waiver (http://creativecommons.org/publicdomain/zero/1.0/) applies to the data made available in this article, unless otherwise stated. 